\title{
Therapeutic interventional endoscopic bail-out in life-threatening surgical complications
}

\author{
Moishe Liberman, MD, PhD
}

\author{
From the Division of Thoracic Surgery, University of Montreal, Montreal, Quebec, Canada. \\ Disclosures: Author has nothing to disclose with regard to commercial support. \\ Received for publication Feb 28, 2017; accepted for publication March 2, 2017; available ahead of print March 28, \\ 2017. \\ Address for reprints: Moishe Liberman, MD, PhD, Division of Thoracic Surgery, Centre Hospitalier de l'Uni- \\ versité de Montréal, 1560 rue Sherbrooke Est, 8e CD-Pavillon Lachapelle, Bureau D-8051, Montréal, Québec, \\ Canada H2L 4M1 (E-mail: moishe.liberman@umontreal.ca). \\ J Thorac Cardiovasc Surg 2017; 154:e21 \\ $0022-5223 / \$ 36.00$ \\ Copyright (c) 2017 by The American Association for Thoracic Surgery \\ http://dx.doi.org/10.1016/j.jtcvs.2017.03.002
}

Therapeutic interventional thoracic endoscopy has become an important adjunct to major thoracic surgery programs over the last decade. We have seen expanded indications for endoscopic interventions both in the preoperative thoracic surgical setting in terms of endoscopically optimizing patients before surgery ${ }^{1}$ and in the postoperative setting $^{2}$ in terms of bailing surgeons out of surgical complications and their associated morbidities. This report by D'Andrilli and colleagues ${ }^{3}$ is a great example of a minimally invasive endoscopic procedure that bailed a patient out of a major morbidity and associated mortality using a bronchoscopic intervention.

In this report, D'Andrilli and colleagues ${ }^{3}$ from Rome describe the successful closure of a complex bronchopleural fistula occurring at 2 sites in the bronchus after a right lower and middle lobe bilobectomy in a patient who had received neoadjuvant chemoradiotherapy for preoperatively identified N2 disease. Vascularized flap buttressing was not used in this case. The patient developed a 3-mm dehiscence of the bronchial staple line and a $2.5-\mathrm{cm}$ ischemic defect on the right main bronchial wall. This is indeed a complex situation to fix surgically and is associated with a high mortality. Two separate techniques were used to fix the holes: a covered stent for the membranous wall defect and an Amplatzer device (St Jude Medical, Saint Paul, Minn) for the staple line defect. Both holes were successfully closed with no associated morbidity at 1-year follow-up.

Complex endoscopic interventions as attempted treatment strategies for patients after thoracic surgery should be performed by skilled endoscopic teams. These procedures not only are technically complex but also require a thoughtful and experienced team approach to decision making and deciphering appropriate indications for endoscopic as opposed to surgical approaches to repair surgical complications. In centers where nonsurgeons are performing

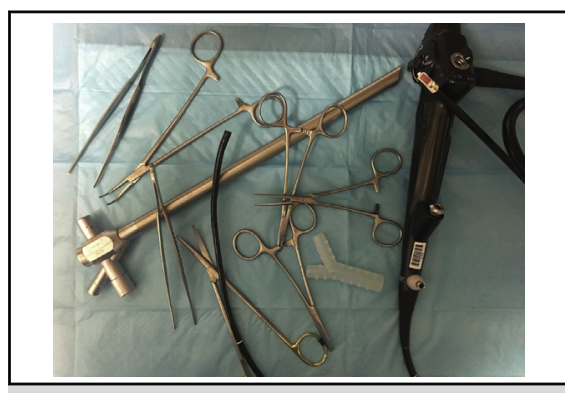

The 2017 thoracic surgeon's toolbox.

Central Message

Advances in interventional thoracic endoscopy have allowed for novel techniques that can, in certain situations, avoid complex surgery in patients with life-threatening thoracic disease.

See Article page e17.

therapeutic endoscopy, a close working relationship and thoughtful discussion before endoscopic intervention in surgical cases are vital to provide the best treatment plan for each patient and not cause unrepairable damage to the tracheobronchial tree, which would make surgical bail-out postendoscopic intervention impossible.

Advances in interventional thoracic endoscopy have allowed for novel techniques that can, in certain situations, avoid complex surgery in patients with thoracic disease. Thoracic surgeons need to be aware of these techniques, to have an open mind, and to consider them on a case-bycase basis as they encounter patients with complications after surgery. Remember, it was not that long ago that the emergency treatment for a bleeding endotracheal or endobronchial tumor was resection.

\section{References}

1. Liberman M. Cleaning the pipes before changing the furnace. endoscopic patient optimization before major therapeutic intervention in lung cancer. $J$ Thorac Cardiovasc Surg. 2016;152:e69.

2. Dutau H, Breen DP, Gomez C, Thomas PA, Vergon JM. The integrated place of tracheobronchial stents in the multidisciplinary management of large postpneumonectomy fistulas: our experience using a novel customised conical selfexpandable metallic stent. Eur J Cardiothorac Surg. 2011;39:185-9.

3. D’Andrilli A, Andreetti C, Menna C, Rendina EA. Successful endoscopic treat ment of severe ischemic damage of the bronchus. J Thorac Cardiovasc Surg. 2017; 154:e17-9. 